\title{
ESTUDIOS DE LA BIOLOGÍA REPRODUCTIVA EN CINCO ACCESIONES DE Smallanthus sonchifolius (Poepp. \& Endl.) ROBINSON
}

\section{REPRODUCTIVE BIOLOGY STUDY IN FIVE ACCESSIONS OF Smallanthus sonchifolius (Poepp. \& Endl.) ROBINSON}

\author{
Roberto Mansilla ${ }^{1}$, César López $^{2}$, Mercedes Flores ${ }^{3}$ y Rosa Espejo ${ }^{4}$
}

\begin{abstract}
Resumen
El yacón (Smallanthus sonchifolius (Poepp. \& Endl.) Robinson) es una tuberosa de la familia Asteraceae que en los últimos años ha generado interés por su importancia medicinal y económica ya que es utilizada como alimento funcional por su contenido de fructo-oligosacáridos. Sin embargo, la baja reproducción sexual es uno de los principales problemas que presenta esta especie en su mejoramiento genético. Por esta razón, para conocer el origen de dicha característica, en el presente trabajo se han realizado estudios de biología floral y reproductiva a cinco accesiones de yacón del Departamento de Huánuco. En la evaluación de la floración, el tiempo de inicio fue distinto entre las accesiones, y demoraron hasta ocho semanas en alcanzar el $100 \%$ de floración. Este prolongado inicio de la floración y la asincrónica formación de los capítulos en la planta favorecerían una polinización cruzada. Además, entre las accesiones se encontró variaciones en los caracteres cuantitativos de las estructuras florales y diferencias en el porcentaje de aquenios con semillas, esto indicó que la capacidad reproductiva es diferente entre las accesiones. Entre tanto, por el estudio del comportamiento de los insectos, se podría decir que el transporte de polen es insecto-dependiente. Sin embargo, la elevada receptividad de los estigmas durante el desarrollo de la inflorescencia, contrasta con los bajos porcentajes de germinación in vitro de los granos de polen $(0.16 \%)$, de los aquenios que presentaron semillas $(11.17 \%)$ y de viabilidad de semillas. Estos aspectos podrían estar relacionados a la presencia de un fragmento de ADN de $202 \mathrm{pb}$ aproximadamente, que fue amplificado con los cebadores de $20 \mathrm{pb}$ que amplifican una zona del orfH522 asociado a la androesterilidad en Helianthus annuus.
\end{abstract}

Palabras clave: yacón, androesterilidad.

Abstract
Yacon (Smallanthus sonchifolius) is a root tuber plant belonging to the botanical family Asteraceae. Recently, it has gained interest for its medicinal and economic importance. It is used as a functional food for its content of fructo-oligosaccharides. A major constraint facing genetic breeding of this crop is its low sexual reproductive capacity. Therefore, we aimed to investigate the floral and reproductive biology of five accessions of yacon in Huanuco. In this work, we observed that flowering time was similar among the accessions and it took eight weeks to reach flowering. This feature and the asynchronous formation of the capitulum in the plant would encourage cross-pollination.

The plant reproductive ability is different among accessions, due to quantitative trait variation in floral structures and differences in the percentage of achenes with seeds.

Taking into account its pollination habits, we consider that it is an insect dependant plant, as evident from insect attraction by the ray floret, the high frequency of visits and insect behavior. The high receptivity of the stigmas present during inflorescence development, contrasts with poor in vitro germination of pollen, few achenes with seeds and low seed viability. These aspects could be related to the presence of a 202 bp DNA fragment, amplified with primers for orfH522 gene associated with male sterility in Helianthus annuus.

Key words: yacón, male sterility.

\section{Introducción.}

Smallanthus sonchifolius ("yacón") es una especie de la familia Asteraceae originaria de la región andina (Robinson, 1978) que crece entre los 2000 y 3500 m.s.n.m. Su cultivo se remonta a épocas precolombinas y ha permanecido por mucho tiempo restringido a áreas muy pequeñas ya que está adaptada a las condiciones ecológicas de los Andes, donde su uso está fuertemente ligado a las tradiciones de los 
pueblos. En los últimos años, el yacón ha despertado interés mundial por sus cualidades hipoglucémicas y como alimento funcional (por su contenido de fructooligosacáridos que influyen en la fisiología humana), permitiendo aumentar su uso potencial en la agroindustria e industria farmacéutica. El pasar de un estado de semidomesticación y restringido a los huertos familiares a otro de áreas de mucha mayor producción genera retos para su mejoramiento, tales como el afrontar nuevos patógenos, acceder a nuevas zonas de cultivo y mantener o generar las características que requiere el mercado. Además, la introducción de estas nuevas características requerirá del pleno conocimiento de la biología reproductiva.

La biología floral es un componente importante para el conocimiento de la biología reproductiva de las plantas de reproducción sexual; investiga las relaciones mutuas entre las flores y su ambiente, vivo y no vivo, con respecto a la polinización (Valla, 1973). En sentido estricto, comprende los procesos de polinización y fecundación y su objetivo es explicar la función de los órganos florales, a través, del análisis de la morfología floral y el comportamiento de los agentes polinizadores.

Morfológicamente, el yacón se caracteriza por tener una inflorescencia en capítulo. La planta de yacón puede tener una o más ramas y cada una de ellas puede formar entre 20 y 40 capítulos, los cuales son terminales y están compuestos de uno a cinco ejes florales. Cada capítulo posee un involucro conformado por 5 a 8 filarias uniseriadas y ovadas y dos tipos de flores: las radiales que son liguladas y las del disco que son tubulares. La flor ligulada mide entre $12 \mathrm{~mm}$ y $16.8 \mathrm{~mm}$ de largo y $7 \mathrm{~mm}$ de ancho (Soto, 1997; Grau \& Rea, 1997), presenta una corola de tubo corto y una prolongación a manera de lengüeta, la lígula, bi o tridentada, que puede ser oblonga, ovalada o elíptica y de color amarillo hasta anaranjado brillante (Seminario et al., 2003). El tamaño y color de la lígula juega un rol importante en la atracción de los polinizadores. Las flores del disco tienen corola tubular y en la parte superior se observan cinco lóbulos iguales. El papus o vilano se localiza en la base de la corola y por encima del ovario. El androceo es sinantéreo y tiene cinco anteras. El gineceo no funcional tiene un pistilo de ovario ínfero, bicarpelar, unilocular y el estilo atraviesa el tubo de la corola y se divide en dos ramas estilares. La corola mide entre $7 \mathrm{~mm}$ (Grau \& Rea, 1997) y $8 \mathrm{~mm}$ de longitud (Soto, 1997). Estas flores se abren por series en la inflorescencia, mostrando las anteras connadas a la parte apical del estilo.

Sin embargo, la escasa reproducción sexual es un rasgo característico de esta especie, cuyo origen aún no claro se le atribuye a factores como: problemas durante la meiosis (debido a su posible origen híbrido), la inviabilidad de sus semillas y la ausencia de polinizadores (Grau \& Rea, 1997). También la alta esterilidad de los granos de polen que fuera observada en diferentes trabajos de investigación realizados tanto en Argentina como en clones ecuatorianos mediante técnicas de coloración diferencial (Grau \& Rea, 1997), posiblemente influiría en la escasa reproducción sexual. Contrariamente, Seminario et al. (2003) sugieren que la reducida reproducción sexual no es debido a la esterilidad de los granos de polen, ya que Soto (1997), mediante tinción con aceto carmín encontró una alta viabilidad del polen. Ante este escenario, se plantea que el origen de la escasa reproducción sexual puede encontrarse en otro factor de la biología reproductiva como la androesterilidad citoplasmática.

La androesterilidad citoplasmática ha sido descrita en más de 150 especies, y conjuntamente con los genes restauradores de la fertilidad fue extensamente usada en la producción de híbridos F1. En las plantas androestériles citoplasmáticas el desarrollo de la antera puede estar muy fuertemente afectado, ó como en algunos mutantes CMS (Cytoplasmic Male Sterility), las anteras pueden desarrollarse normalmente, pero la microsporogénesis se detiene durante la meiosis o mucho después. Generalmente en plantas CMS, el tapetum de la antera sufre degradación celular durante la meiosis, seguido mucho después de la muerte de las microsporas inmaduras (Balk \& Leaver, 2001). Sin embargo, algunos genotipos CMS pueden estar enmascarados por la presencia de genes nucleares restauradores de la fertilidad (Johns et al., 1992).

En muchos casos el carácter androesterilidad citoplasmática está asociado a unos raros Marcos de Lectura Abiertos (Open Reading Frames, ORFs) del genoma mitocondrial, y en otros casos como en el tabaco, a la pérdida de genes mitocondriales. Se cree que dichos ORFs se originaron por eventos aberrantes de recombinación de los genomas mitocondriales. También, las secuencias de los ORFs a veces contienen porciones parciales de genes mitocondriales y pueden ser transcritos conjuntamente con otros genes funcionales (Balk \& Leaver, 2001).

El objetivo en el presente estudio fue realizar evaluaciones en aspectos de la biología floral y reproductiva del yacón que permitan entender su baja capacidad reproductiva por la vía sexual.

\section{Materiales y métodos.}

Material vegetal.

El material vegetal estuvo compuesto por 9 a 10 plantas de 5 accesiones provenientes del Banco de Germoplasma de la Universidad Nacional Hermilio Valdizán, de Huánuco (Tabla 1) que estuvieron sembradas en el Huerto Olerícola y Frutícola del Fundo Cayhuayna, Distrito de Pillco Marca, ubicado a una altitud de 1964 msnm. 
Tabla 1. Datos de origen del material vegetal usado en el estudio.

\begin{tabular}{cccccc}
\hline Accesión & Código & Provincia & Distrito & Localidad & $\begin{array}{c}\text { Altitud } \\
(\mathrm{msnm})\end{array}$ \\
\hline 66 & HCSS66 & Pachitea & Chaglla & Asunción & 2800 \\
70 & HCSS41 & Huacrachuco & Quillabamba & Ututo & 3000 \\
71 & HCSS71 & Pachitea & Chaglla & Panaopampa & 2900 \\
79 & HCSS79 & Huacrachuco & Marcapata & Marcapata & 3035 \\
80 & HCSS80 & Huacrachuco & Yanas & Yanas & 3150 \\
\hline
\end{tabular}

Caracteres de las estructuras florales y los polinizadores.

Se evaluaron los siguientes caracteres: número de flores liguladas, número de flores tubulares, longitud del estigma y de la lígula. Algunos datos se tomaron en el campo y otros en los laboratorios del Instituto de Biotecnología de la Universidad Nacional Agraria La Molina.

Los polinizadores e insectos asociados a las flores del yacón fueron observados y colectados desde las 7 horas hasta las 18 horas en 7 días no consecutivos, con intervalos de 1 y 2 semanas entre ellos. Así mismo, se describió el comportamiento de los visitantes más frecuentes por observación directa y por análisis fílmico y fotográfico. Se anotó la hora de entrada y salida del animal, para determinar el periodo de permanencia en la inflorescencia, así como el estado del tiempo durante su visita.

Análisis estadístico.

Para los caracteres cuantitativos se realizó el análisis de varianza comparándose luego las medias mediante la prueba de Duncan ( $\alpha=0.05$ ). Además, se realizó el análisis de correlación de Pearson entre las variables evaluadas. El programa estadístico empleado fue SPSS 13.0.

Caracteres reproductivos.

Floración,

El periodo de evaluación de la floración comprendió entre el 30 de enero y el 27 de marzo de 2005. Las condiciones de tiempo en la zona de estudio fueron: temperatura máxima promedio anual de 26.6 ${ }^{\circ} \mathrm{C}$, mínima de $12.8{ }^{\circ} \mathrm{C}$. Humedad relativa que fluctúa de $88 \%$ (7 horas) y $41 \%$ (13 horas). En este estudio, se consideró como inicio de la floración la aparición de los botones florales.

Germinación del tubo polínico.

El medio de cultivo para la germinación del tubo polínico consistió en, $\mathrm{H}_{3} \mathrm{BO}_{3} 100 \mathrm{ppm}, \mathrm{Ca}\left(\mathrm{NO}_{3}\right)_{2} \cdot \mathrm{H}_{2} \mathrm{O}$, $300 \mathrm{ppm}, \mathrm{MgSO}_{4} .7 \mathrm{H}_{2} \mathrm{O} 200 \mathrm{ppm}$, y $\mathrm{KNO}_{3} 100 \mathrm{ppm}$ con $30 \%$ de sacarosa, se obtuvo variando el medio para papa de Rihova et al. (1996), con el cual, se observaron menos granos de polen reventados. El criterio usado para considerar un grano de polen germinado, fue que la longitud del tubo polínico sea mayor o igual al diámetro de dicho grano (Vaknin et al., 2003; Rihova et al., 1996).

Periodo de la antesis.

La evaluación de la antesis de las flores liguladas se realizó mediante la observación de la receptividad del estigma en el campo entre las 10 y 12 horas. Para ello fue necesario determinar 3 estadios de desarrollo en el capítulo. El primer estadio cuando las flores tubulares aun permanecen cerradas, el segundo estadio cuando están abiertas las flores tubulares hasta la tercera hilera y el tercero, cuando las flores están abiertas desde la cuarta hilera hasta la totalidad de flores tubulares. La receptividad del estigma floral se determinó mediante el método del burbujeo de estigmas y estilos en solución de peróxido de hidrógeno 2.68 M (Dafni, 1992).

Viabilidad de las semillas.

Para determinar la viabilidad de la semilla (aquenios), ésta fue extraída del aquenio y separada de su tegumento. La prueba de viabilidad mediante tinción con Tetrazolium (2,3,5-triphenyl tetrazolium chloride)(Kamenetsky et al., 2005; Peters, 2000), fue realizada a 397 semillas.

Búsqueda de la presencia de secuencias de ADN relacionadas a la androesterilidad citoplasmática.

Para entender si la baja capacidad de reproducción sexual del yacón es explicada por la androesterilidad citoplasmática, se buscaron secuencias en el Gen Bank para este carácter en especies dentro de la familia Asteraceae a la que pertenece $S$. sonchifolius y en otras familias que presentan el carácter de androesterilidad. Con las secuencias halladas se diseñaron los iniciadores mediante el programa Primer3 (Rozen \& Skaletsky, 2006) los que fueron sintetizados por la empresa Genlab del Perú SAC.

Estos cebadores fueron utilizados mediante el siguiente procedimiento:

Extracción de ADN, amplificación y electroforesis..

La extracción ADN se realizó a partir de hojas jóvenes según el protocolo modificado de Doyle \& Doyle (1990), (tampón de extracción CTAB $3 \%, 2.1 \mathrm{M}$ de $\mathrm{NaCl}, 250 \mathrm{mM}$ de Tris $\mathrm{HCl} \mathrm{pH} 8,50 \mathrm{mM}$ de EDTA pH 8 y $2 \mu \mathrm{l} /$ reacción de ß-mercaptoetanol). La amplificación de secuencias específicas se realizó en el termociclador Perkin Elmer 9700. El mix de amplificación estuvo constituido por: Tampón $0.5 \mathrm{X}$; DNA 26 ng/reacción; Taq ADN polimerasa 2 U/reacción; iniciadores $0.625 \mu \mathrm{M}$ de cada uno; dNTPs $0.338 \mathrm{mM}$ de cada uno y $\mathrm{MgCl}_{2} 3.5 \mathrm{mM}$. El perfil de amplificación fue el siguiente: 1 ciclo a $94{ }^{\circ} \mathrm{C}$ por 5 minutos, luego de 35 ciclos de $94^{\circ} \mathrm{C}$ por 60 segundos, $55{ }^{\circ} \mathrm{C}$ por 45 segundos y $72{ }^{\circ} \mathrm{C}$ por 60 segundos; y finalmente de 1 ciclo de $72{ }^{\circ} \mathrm{C}$ por 7 minutos y $4{ }^{\circ} \mathrm{C}$ hasta retirar las muestras del termociclador. Los productos de amplificación fueron separados mediante electroforesis horizontal en geles de agarosa al $2.5 \%$ con tampón TBE, y corridos por 2 horas a 100 voltios, utilizando una solución tampón de carga (Azul de Bromofenol $0.21 \%$, Xilencianol FF $0.21 \%$, EDTA $0.2 \mathrm{M} \mathrm{pH} 8$, Glicerol $50 \%$ ). La preparación de los 
geles se realizó mediante el procedimiento recomendado por International Triticale Mapping Initiative (1994). La visualización de los fragmentos amplificados se realizó mediante un transiluminador UV previa tinción con bromuro de etidio $0.5 \mathrm{mg} / \mathrm{ml}$. la longitud de la lígula se mantendrá en valores más o menos constantes sin importar lo grande que sea la inflorescencia, por lo tanto el incremento del diámetro del disco sólo dependerá del aumento del número de flores masculinas.
Resultados y discusión.

Caracteres de las estructuras florales y los polinizadores.

En la Tabla 2 se muestran los resultados de las evaluaciones de los caracteres cuantitativos de las estructuras florales realizadas a las 5 accesiones de yacón. El análisis de variancia para cada uno de los 4 caracteres evaluados (número de flores liguladas, número de flores tubulares, longitud del estigma y longitud de la lígula) ha mostrado diferencias altamente significativas entre las accesiones, por lo tanto, mediante la prueba de comparación de medias de Duncan, se observa que las accesiones se agruparon en 2, 4, 2 y 3 grupos respectivamente tal como se muestra en las tablas 2 y 3 , sin embargo solamente se formaron grupos definidos para los números de flores tubulares y liguladas (Tabla3).

Correlaciones.
Tabla 3. Agrupamientos realizados mediante la prueba de comparación de medias de Duncan $(=0.05)$.

\begin{tabular}{lcccccccc}
\hline & Caracteres evaluados & $\begin{array}{c}\text { Grupos } \\
\text { Definidos }\end{array}$ & 66 & 70 & 71 & 79 & 80 \\
\hline Flores & Longitud de la lígula & No & a & c & a & c & b \\
& Longitud del estigma & No & a & b & b & a & a \\
& Número flores tubulares & $\mathrm{Si}$ & $\mathrm{d}$ & $\mathrm{a}$ & $\mathrm{b}$ & $\mathrm{d}$ & $\mathrm{c}$ \\
& Número flores liguladas & $\mathrm{Si}$ & $\mathrm{b}$ & $\mathrm{a}$ & $\mathrm{a}$ & $\mathrm{b}$ & $\mathrm{a}$ \\
\hline
\end{tabular}

En cada carácter cada letra representa un grupo.

Polinizadores.

Los principales polinizadores de yacón en la zona de evaluación fueron: Pieris brassicae, Danaus sp., Mellipona cf. nigrescens, Rubrica surinamensis, Metasirfus sp., Apis sp., Bombus coccineus, Scolia sp., y los grupos Colletidae, Halictidae (Tabla 4 y Figura 2).

La mariposa Pieris brassicae es la que más tiempo de permanencia tuvo en la inflorescencia, ( 8 minutos

Tabla 2. Caracteres evaluados en las 5 accesiones de yacón.

\begin{tabular}{|c|c|c|c|c|c|c|c|}
\hline Accesión & $\begin{array}{l}\text { Promedio de } \\
\mathrm{N}^{\mathrm{o}} \text { de flores } \\
\text { liguladas }\end{array}$ & $\begin{array}{l}\text { Promedio } \\
\text { de } \mathrm{N}^{\mathrm{o}} \mathrm{de} \\
\text { flores } \\
\text { tubulares }\end{array}$ & $\begin{array}{l}\text { Promedio } \\
\text { de } \\
\text { Longitud } \\
\text { del } \\
\text { estigma } \\
(\mathrm{mm})\end{array}$ & $\begin{array}{l}\text { Promedio } \\
\text { de } \\
\text { Longitud } \\
\text { de la } \\
\text { lígula } \\
(\mathrm{mm}) \\
\end{array}$ & $\begin{array}{c}\text { Germinación } \\
\text { del tubo } \\
\text { polínico }(\%)\end{array}$ & $\begin{array}{c}\text { Receptividad } \\
\text { del estigma } \\
(\%)\end{array}$ & $\begin{array}{c}\text { Porcentaje } \\
\text { de aquenios } \\
\text { con } \\
\text { semillas }\end{array}$ \\
\hline 66 & 14.50 & 74.81 & 4.14 & 7.51 & 0 & 55.55 & 1.62 \\
\hline 70 & 16.25 & 132.25 & 3.46 & 6.89 & 0.133 & 100.00 & 11.11 \\
\hline 71 & 15.90 & 106.45 & 3.40 & 7.33 & 0.150 & 96.67 & 19.72 \\
\hline 79 & 13.67 & 68.61 & 3.75 & 6.61 & 0.092 & 81.48 & 8.86 \\
\hline 80 & 16.31 & 84.27 & 3.90 & 6.99 & 0.037 & 88.89 & 17.24 \\
\hline ANVA & $* *$ & $* *$ & $* *$ & $* *$ & - & - & - \\
\hline $\begin{array}{l}\mathrm{N}^{\mathrm{o}} \text { de Grupos } \\
\text { Formados mediante } \\
\text { prueba de DUNCAN } \\
(\alpha=0.05)\end{array}$ & 2 & 4 & 2 & 3 & - & - & - \\
\hline
\end{tabular}

Los análisis de correlación fueron altamente significativos entre la longitud de la lígula y del estigma $(r=0.391)$ y entre el número de flores tubulares y el número de flores liguladas $(\mathrm{r}=0.400)$. Por lo tanto, si el número o la densidad de flores tubulares se incrementan o disminuyen, el número de flores liguladas en el disco de la inflorescencia también seguirá esa tendencia.

Sin embargo, no existe correlación entre la longitud de la lígula y el número de flores liguladas ( $\mathrm{r}$ $=-0.003)$, y existe una correlación muy baja entre el número de flores tubulares y la longitud de la lígula ( $\mathrm{r}$ $=0.104, \mathrm{sig}=0.305)$. Este resultado lleva a pensar que aproximadamente) seguida de Apis sp. (4 minutos aproximadamente).

El mayor número de visitas sucedió cuando el ambiente estaba soleado, y las frecuencias disminuyeron cuando se presentaron lluvias o lloviznas. Por otro lado, en días nublados predominaron las visitas de insectos grandes. Las horas en que ocurrieron las mayores visitas fueron entre las 10 de la mañana y 4 de la tarde. Adicionalmente, se observó la presencia de depredadores de polinizadores como arácnidos y avispas (Tabla 4). 
En relación al comportamiento de los insectos visitantes, estos primero se posan sobre las flores liguladas, y posteriormente sobre las flores tubulares. En el disco de la inflorescencia, las abejas y abejorros, sobre las corolas de las flores cerradas y las anteras y pistilos con abundante polen que sobresalen de las flores abiertas, se mueven en círculos inspeccionando una por una todas las flores. Sin embargo, los insectos grandes como la mariposa monarca, debido a su mayor peso ocasiona que la inflorescencia se incline en posición vertical, y se sujete mediante sus extremidades anteriores de las flores liguladas y del involucro. Con el capítulo en esta posición inspecciona primero las flores que quedaron en la zona inferior y luego desplazándose en zig zag avanza hacia la zona superior, deteniéndose en cada flor. Las avispas, de forma similar a las abejas y abejorros se posan sobre el disco, mientras que algunas, probablemente ingieren los granos de polen y el néctar de estas flores, otras buscan atrapar insectos que son atraídos por las inflorescencias. Debido al mayor tiempo de permanencia y a su comportamiento particular en la inflorescencia, las abejas y los abejorros serían los polinizadores más eficientes del yacón.

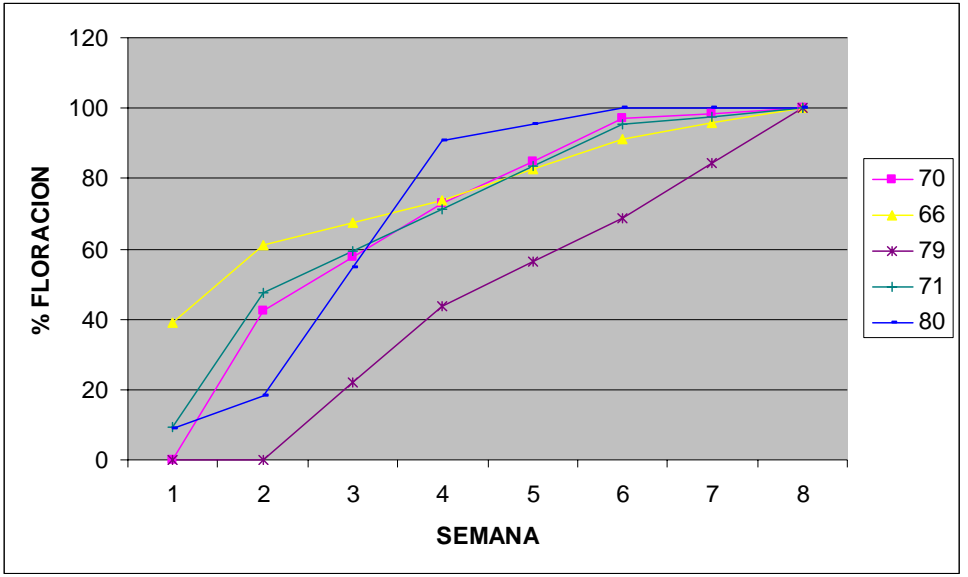

Figura 1. Gráfico del tiempo (semanas) versus floración (\%).

alcanzó el 100 \% de plantas en floración. De otro lado, la accesión 79 fue la más tardía en iniciar la floración y en alcanzar el $100 \%$ de plantas en floración. En la octava semana de evaluación, el total de las plantas de todas las accesiones ya se encontraban en floración (Figura 1). Luego se inició el periodo de senescencia, durante el cual se realizó la cosecha de las raíces tuberosas.

Receptividad del estigma.

La evaluación de la receptividad del estigma se realizó entre las 10 y 12 horas del día en la sexta y séptima semana de evaluación, cuando la mayoría de las plantas habían iniciado la floración. Fue aplicada a

flores liguladas que tenían las ramas

Tabla 4. Especies y grupos de insectos observados en flores de yacón en la provincia de Huánuco de Febrero a Mayo 2005.

\begin{tabular}{|c|c|c|c|}
\hline GÉNERO - ESPECIE & $\begin{array}{c}\text { TIEMPO } \\
\text { APROXIMADO } \\
\text { DE } \\
\text { PERMANENCIA } \\
\text { EN LA FLOR }\end{array}$ & $\begin{array}{c}\text { CONDICIONES } \\
\text { DEL } \\
\text { AMBIENTE EN } \\
\text { EL QUE SE } \\
\text { PRESENTA }\end{array}$ & $\begin{array}{c}\text { FRECUENCIA } \\
\text { (visitas } \\
\text { observadas) }\end{array}$ \\
\hline Pieris brassicae & $1 \min -8 \min$ & Soleado & $>45$ \\
\hline Colletidae & $2 \min$ & nublado y soleado & 12 \\
\hline Bombus coccineus & $3 \mathrm{~min}$ & Soleado & 4 \\
\hline Mellipona cf nigrescens Fries 1900 & $3 \mathrm{~min}$ & nublado y soleado & 12 \\
\hline Halictidae & $2 \min -3 \min$ & soleado mas & $>16$ \\
\hline Rubrica surinamensis & $3 \min$ & nublado y soleado & $>34$ \\
\hline Danaus sp. & $2 \min$ & nublado y soleado & $>53$ \\
\hline Metasirfus & $1 \mathrm{~min}$ & Soleado & 4 \\
\hline Apis sp. & $4 \mathrm{~min}$ & nublado y soleado & 12 \\
\hline Scolia sp. & $2 \min$ & nublado y soleado & 7 \\
\hline
\end{tabular}
estigmáticas separadas (Tabla 2), produciendo reacción positiva para flores del primer estadio en un $75.56 \%$, para flores segundo estadio en un $93.75 \%$ y para flores del tercer estadio en un $83.33 \%$. Germinación del tubo polínico.

El porcentaje de germinación de los granos de polen fue bastante bajo en las diferentes accesiones estudiadas (Tabla 2). Viabilidad de semillas.

Caracteres reproductivos.

Floración.

La floración se consideró desde la aparición de los primeros capítulos en la planta. Al inicio de la evaluación la accesión 66 ya presentaba plantas que habían iniciado la floración; sin embargo, esta fue la penúltima en alcanzar el $100 \%$ de plantas en floración. La accesión 80 fue la que en menor tiempo

Tan solo una de las 397 semillas obtenidas entre las 5 accesiones presentó coloración en la radícula, considerándose esta señal suficiente para aceptar su viabilidad, por lo tanto, la viabilidad en las semillas evaluadas fue de $0.25 \%$. 
Búsqueda de la presencia de secuencias de ADN relacionadas a la androesterilidad citoplasmática.

Mediante la búsqueda de genes de androesterilidad citoplasmática en la base de datos del NCBI se seleccionaron cuatro secuencias pertenecientes a especies distintas de la clase Dycotiledoneae que son cercanas taxonómicamente a $S$. sonchifolius. (Tabla 5). A partir de cada una de ellas se diseñaron un par de iniciadores de 20 nucleótidos de longitud que permitieron amplificar fragmentos entre 206 a 237 pares de bases, cuyas temperaturas de melting están próximas a $60{ }^{\circ} \mathrm{C}$ (Tabla 6 ).

El par de iniciadores de orfH522 correspondiente a Helianthus annuus, amplificó un fragmento de aproximadamente 202 pares de bases con el ADN de yacón. No amplificaron fragmentos utilizando iniciadores diseñados para el ORF-167 de Beta vulgaris; el ORF-456 de Capsicum annuum; ni para el ORF-138 de Rhapanus sativus.

\section{Discusión.}

La elevada correlación entre el número de flores tubulares y el número de flores liguladas hace creer que la expresión génica responsable de la diferenciación sexual varía radialmente en el capítulo, tal como en Gerbera hybrida (Laitinen et al., 2006), en la cual, los primordios florales exteriores indiferenciados del capítulo, en sus primeros estadios de formación, tienden a desarrollarse como flores femeninas al abortarse las anteras; mientras que, los del interior del disco se desarrollan como bisexuales (Yu et al., 1999).

La variación en los caracteres morfológicos hallada entre las accesiones, en términos reproductivos, determinará la variación de algunos factores como: el área del elemento de atracción, el área de la zona de contacto con los polinizadores y el número de granos de polen puestos a disposición para la polinización, los cuales influyen en la capacidad reproductiva. Lo que explicaría el hecho del porque las accesiones 66 y 79 con menor promedio de flores tubulares presentaran los menores porcentajes de aquenios con semillas (Tabla 2). Debido a la correlación altamente significativa entre la longitud de la lígula y la longitud del estigma, el desarrollo de la lígula estaría determinando el desarrollo del estigma, y

Tabla 5. ORFs relacionados a la androesterilidad citoplasmática utilizados para diseño de iniciadores y las especies de la cual proceden.

\begin{tabular}{cccc}
\hline ORF & Organismo & Famila & $\begin{array}{c}\text { Localización } \\
\text { del Gen }\end{array}$ \\
\hline orfH522 & Helianthus annuus & Asteraceae & Mitocondria \\
ORF167 & Beta vulgaris & Amaranthaceae (1) & Mitocondria \\
ORF456 & Capsicum annuum & Solanaceae & Mitocondria \\
ORF138 & Raphanus sativus & Brassicaceae & Mitocondria
\end{tabular}

(1) Considerada en la familia Amaranthaceae según la APG, Judd et al. (1999). que el periodo de crecimiento de la lígula sería similar al del estigma. Además, la evaluación del número de

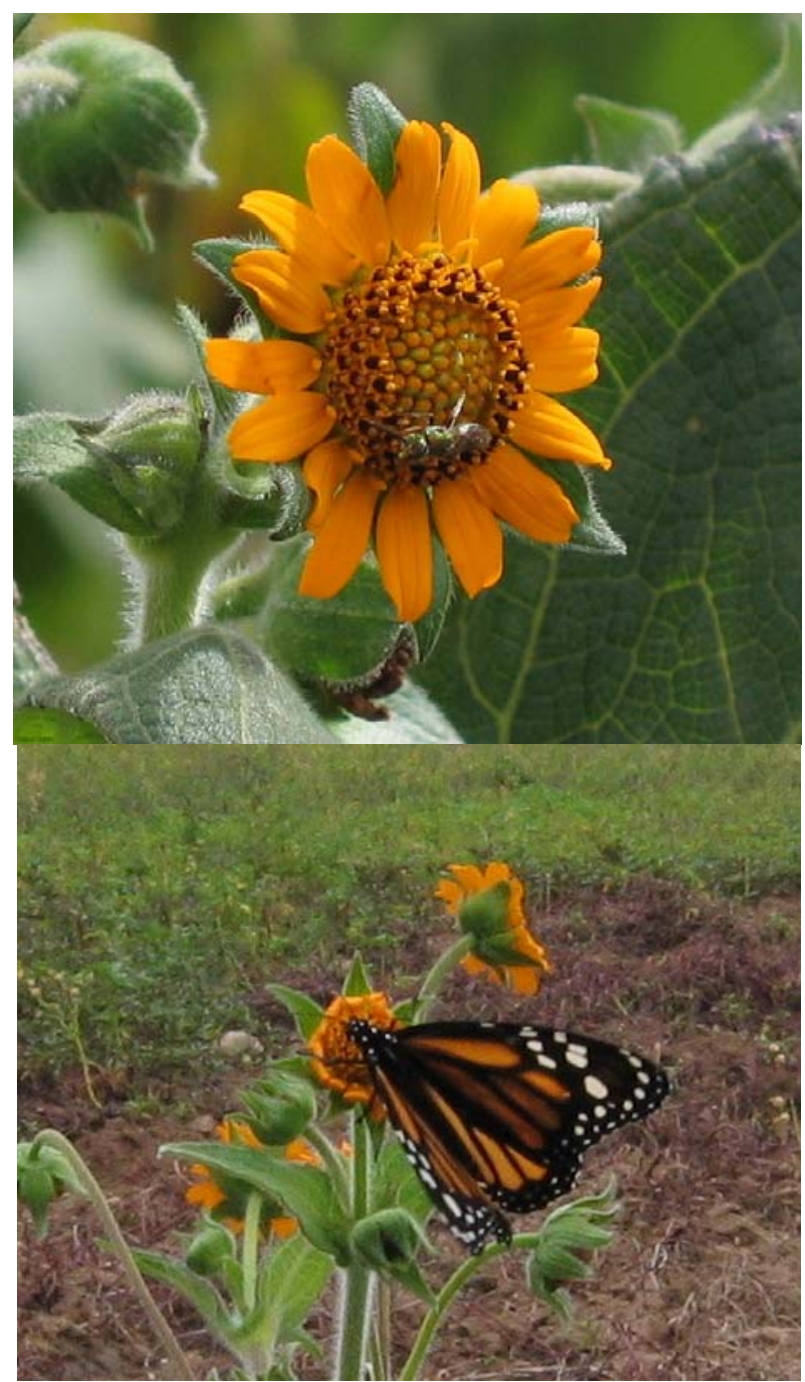

Figura 2. Especies de insectos visitando la flor de yacón, Halictidae sp. (arriba) y Danaus sp. (abajo).

flores tubulares, mostró que las accesiones 70 y 71 superan al rango determinado para esta especie por Seminario et al. (2003), mientras que todos los valores del número de flores liguladas están dentro de los límites reportados por Seminario et al. (2003) y Soto (1997).

Con el estudio de la morfología floral y de los polinizadores en yacón se podría decir que el transporte del polen es insecto dependiente. La forma de la inflorescencia en capítulo sugiere que el yacón atrae a los insectos generalistas, así como sucede en Grindelia covasii (Asteraceae), en donde el hospedero es mas importante para el visitante que el caso contrario (Roitman, 1999).

No solamente el color de las flores liguladas es el objeto de atracción de 
muchos insectos polinizadores, también lo sería el potencial aporte calórico que les brindarían sus abundantes granos de polen (Petanidou \& Vokou, 1990). En consecuencia, los insectos adhieren los granos de polen a sus cuerpos en un espacio amplio de apoyo que representa el disco de la inflorescencia. deban a la influencia de factores del medio ambiente, así como, a las diferencias genotípicas. Sin embargo, de forma similar como sucede en papa (Trognitz, 1991), las técnicas de tinción estarían ofreciendo valores más altos de viabilidad de polen en yacón que los ofrecidos mediante germinación in vitro.

Tabla 6. Características y secuencias de los iniciadores diseñados a partir de los genes relacionados a la androesterilidad citoplasmática.

\begin{tabular}{ccccccc}
\hline Organismo & Lado & $\begin{array}{c}\text { Inicio } \\
\left(\mathrm{N}^{\circ} \text { Base }\right)\end{array}$ & $\begin{array}{c}\text { Longitud } \\
(\text { Bases })\end{array}$ & $\begin{array}{c}\text { Longitud } \\
\text { del } \\
\text { fragmento } \\
(\mathrm{pb})\end{array}$ & $\begin{array}{c}\text { Tm } \\
\left({ }^{\circ} \mathrm{C}\right)\end{array}$ & Secuencia \\
\hline H. annuus & Iniciador Izquierdo & 321 & 20 & 207 & 60.04 & TCTTCCCCCTTTGGAGTCTT \\
& Iniciador Derecho & 527 & 20 & & 60.04 & TAATGGGGAACATCGAGAGC \\
B. vulgaris & Iniciador Izquierdo & 121 & 20 & 206 & 59.86 & GTAGTCAAACCGGCAACCAT \\
& Iniciador Derecho & 326 & 20 & & 60 & GCTTGCTTGAGCCCGTATAG \\
C. annuum & Iniciador Izquierdo & 35 & 20 & 237 & 60.11 & AACCAGCAATTTCCGACAAG \\
& Iniciador Derecho & 271 & 20 & & 60 & GCAGTTCTGCTTCCGTTTTC \\
R. sativus & Iniciador Izquierdo & 106 & 20 & 224 & 59.7 & GCCCATATTTGGCTAAGCTG \\
& Iniciador Derecho & 329 & 20 & & 60.12 & ATTTCCCCTTTCCCCTCTTT \\
\hline
\end{tabular}

$\mathrm{Tm}=$ temperatura de Melting $\left({ }^{\circ} \mathrm{C}\right), \mathrm{pb}=$ pares de bases.

Tanto los caracteres morfológicos de las estructuras florales como el comportamiento de los polinizadores hacen del yacón una especie especializada para la reproducción preferentemente alogámica, sin embargo, no necesariamente garantizarían el éxito de la reproducción sexual.

Caracteres como la floración y receptividad floral explicarían el origen de la variabilidad observada en este cultivo (Mansilla et al., 2006), mientras que la viabilidad gamética y viabilidad de la semilla explicarían su escasa reproducción sexual.

La variabilidad en el tiempo para iniciar la floración entre las accesiones podría deberse a factores genéticos, ambientales, la interacción del genotipo con el medio ambiente ó de otros factores como la condición y el tamaño de la semilla (cepa) empleada en la propagación. Es de esperarse que el éxito en la reproducción de las plantas depende de la floración sincronizada de todos los individuos de una misma población (Blázquez, 2000). Sin embargo, un periodo de inicio de la floración largo en un solo genotipo y distinto entre genotipos, propiciaría la polinización cruzada, característica presente en el yacón (Seminario et al., 2003; Grau \& Rea ,1997).

Mientras que los resultados obtenidos de la prueba de germinación del tubo polínico son similares a los hallados mediante técnicas de tinción por Grau \& Slanis (1996) y Grau \& Rea (1997); y los de polinización dirigida (Grau ,1993); sin embargo, los resultados logrados en este estudio no concuerdan con los de Soto (1997), quien obtuvo elevada fertilidad de granos de polen en clones cajamarquinos utilizando técnica de tinción. Es posible que dichas diferencias se
Debido a que el estigma se muestra receptivo gran parte del tiempo en que el capítulo se encuentra abierto, exceptuando en aquellas flores donde las ramas del estigma no se llegaron a separar, no habría efecto del gineceo sobre la baja producción de semillas sexuales. Entre tanto, la casi nula viabilidad de las semillas, en cierta forma corrobora lo reportado por Meza (1995) quien en la prueba de germinación de semillas obtiene sólo una semilla germinada de 300 sembradas. Sin embargo, contrariamente, Chicata (1998) mediante pruebas de Tetrazolium y de emergencia de semillas, encontró aproximadamente $81 \%$ de viabilidad de semillas. En el presente trabajo la prueba de viabilidad de semillas se realizó cuatro meses después de haber sido recolectados los aquenios del campo, durante este tiempo es posible pudo ocurrir la pérdida de viabilidad.

El fragmento amplificado de 202 pares de bases, podría ser parte del orfH522 presente en girasol, y de forma similar sería responsable de la androesterilidad citoplasmática en el yacón. El orfH522 de 876 pb está asociado a una clase de Muerte Celular Programada del tapetum de la antera (Balk \& Leaver, 2001) codifica un polipéptido de $15 \mathrm{Kd}$ que se cotranscribe con el gen atp1 (Monéger et al., 1994), y presenta una secuencia de 19 pb homólogas a atp8 que es parte del componente $\mathrm{F}_{\mathrm{o}}$ de la ATPasa (Sabar et al., 2003), el cual, se cree pudo ser formado por un evento de recombinación envolviendo una inversión/inserción en el extremo 3' del gen atp1 (Monéger et al., 1994).

De darse el caso que el fragmento amplificado en el presente estudio sea responsable de la androesterilidad citoplasmática en yacón, el gen o los 
genes que dan origen a este carácter, estarían siendo conservados en algún grado en la familia Asteraceae. La androesterilidad citoplasmática que es la ausencia de granos de polen funcionales, es uno de los factores que podría estar involucrado en los problemas de los yacones estudiados y por lo tanto sería una causa de la casi nula reproducción sexual. La androesterilidad citoplasmática, es consecuencia de interacciones disturbadas entre el núcleo y la mitocondria, consecuentemente es de herencia materna; por lo tanto, es común producir plantas androestériles combinando el genoma de una especie con la mitocondria de otra; siendo denominadas las plantas originadas de esta forma como androestériles citoplasmáticas aloplásmicas (Leino, 2005). En tal sentido, es probable que el yacón tenga un origen híbrido, y proceda de la combinación de los genomas de Smallanthus macroscypus y Smallanthus riparius (Grau \& Rea, 1997), y se produjo la interacción del genoma nuclear de una especie con el genoma mitocondrial de la otra, lo que probablemente provocó la androesterilidad citoplasmática aloplásmica de $S$. sonchifolius. Por lo tanto, se plantea la posibilidad de recuperar la fertilidad en yacón con la introducción de genes restauradores de la fertilidad, provenientes de las especies del género Smallanthus que le dieron origen.

\section{Conclusiones.}

En las accesiones de yacón evaluadas el prolongado inicio de la floración y la asincrónica formación de los capítulos en la planta favorecen la polinización cruzada.

Debido a las diferencias, en el inicio de la floración, en los caracteres cuantitativos de las estructuras florales y en el porcentaje de aquenios con semillas halladas, la capacidad reproductiva sexual es distinta entre las accesiones.

Por la elevada frecuencia de visitas y el comportamiento de los polinizadores se diría que el transporte del polen es insecto dependiente, siendo los principales insectos polinizadores en la zona de estudio: Pieris brassicae, Halictidae sp., Rubrica surinamensis, Danaus sp., Melipona $c f$. nigrescens y Apis sp.

Pese a presentar elevada receptividad de los estigmas durante todo el desarrollo del capítulo sólo el $11.71 \%$ de los aquenios de las accesiones presentarían semillas y con casi nula viabilidad. Así mismo, la germinación de los granos de polen es menor a $0.16 \%$ que podría deberse a la presencia de un fragmento de ADN de 202 pb aproximadamente, que fue amplificado con los cebadores para el orfH522 asociado a la androesterilidad en Helianthus annuus.

\section{Agradecimientos.}

A la Cooperación Internacional de Universidades Francófonas por el financiamiento.
A la Mg. Sc. Milka Tello docente de la Universidad Nacional Hermilio Valdizán de Huánuco por las facilidades prestadas y el material vegetal.

A los Investigadores del Instituto de Biotecnología de la Universidad Nacional Agraria La Molina (UNALM) por el apoyo.

\section{Literatura citada.}

Balk J. \& Leaver C. 2001. The PET1-CMS Mitochondrial Mutation in Sunflower Is Associated with Premature Programmed Cell Death and Cytochrome $c$ Release. The Plant Cell. Vol. 13. 1803-1818.

Blázquez M. A. 2000. Bases moleculares de la floración. Ciencia al Día Internacional, Vol. 3 Num. 3: 1 - 12.

Chicata R. 1998. Variabilidad de la semilla botánica y comparación de progenies y clones provenientes del germoplasma de yacón (Polymnia sonchifolia). Tesis para optar el Título de Ingeniero Agrónomo. Universidad Nacional de San Antonio Abad del Cusco.

Dafni A. 1992. A Pollination ecology: a practical approach. New York: IRL, $250 \mathrm{p}$.

Doyle J. J. \& Doyle J. L. 1990. Isolation of DNA from small amounts of plant tissue. BRL Focus 12: 13-15.

Grau A. 1993. Yacon: A highly productive root crop. New Plants Dossier No. 9 Crop \& Food Research Institute Internal Report, Biodiversity Programme, Invermay, New Zealand.

Grau A. and Slanis A. 1996. Is Polymnia sylphioides var. perennis a wild ancestor of yacon? Resumos I Congresso Latino Americano de Raízes Tropicais. CERAT-UNESP, São Pedro, Brasil.

Grau A. \& Rea J. 1997. Yacón, Smallanthus sonchifolius (Poepp. \& Endl) H. Robinson. In: Hermann M. \& J. Heller (eds): Andean roots and tuber: Ahipa, arracacha, maca, yacón. IPGRI, Roma Italia. Páginas 199-242.

International Triticale Mapping Initiative (ITMI). 1994. Wheat Mapping Workshop Laboratory Manual. Cornell University, USA.

Johns C., Lu M., Lyznik A. \& Mackenzie S. 1992. A Mitochondrial DNA Sequence is Associated whit Abnormal Pollen Development in Cytoplasmic Male Sterile Bean Plants. The Plant Cell. Vol. 4: 435-449.

Judd W. S., Campbell C. S., Kellog E. \& Stevens P. F. 1999. Plant Systematic. A Phylogenetic Approach. Sinauer Associates, Inc., Massachusetts, USA.

Kamenetsky R., London Shafir I., Khassanov F., Kik C., Van Hedsden A.W., Vrielink-Van Ginkel M., BurgerMeijer K., Augers J., Arnault I. \& Rabinowitch H.D. 2005. Diversity in fertility potential and organo-sulphur compounds among garlics from Central Asia Biodiversity and Conservation Springer 2005 14: 281295.

Laitinen R., Broholm S., Albert V.A., Teeri T. \& Elomaa P. 2006. Patterns of MADS-box gene expression mark flower-type development in Gerbera hybrida (Asteraceae). BMC Plant Biology. 6-11.

Leino M. 2005. Mitochondrial Genetics of Alloplasmic Male-Sterile Brassica napus Lines. Doctoral Thesis, Swedish University of Agricultural Sciences. Uppsala.

Mansilla R., López C., Blas R., Chia J. \& Baudoin J., 2006. Análisis de la Variabilidad Molecular de una Colección Peruana de Smallanthus sonchifolius (Poepp \& Endl) H. Robinson "Yacón" Ecol. apl. 5 (1 y 2): 75-80. 
Meza G. 1995. Variedades nativas de Llacon (Polymnia sonchifolia Ker Gawler) en Cusco. UNSAC-CICA, Kayra; CIP-COTESU.

Monéger F., Smart C. \& Leaver C. 1994. Nuclear restoration of cytoplasmic male sterility in sunflower is associated with the tissue-specific regulation of a novel mitochondrial gene. EMBO J., 13: 8 - 17.

Petanidou T. \& Vokou D. 1990. Pollination and Pollen Energetics in Mediterranean Ecosystems. Amer. J. Bot. 77(8): 986-992.

Peters J. 2000. Tetrazolium Testing Handbook 2000. Association of Official Seed Analysts (AOSA), Contribución No. 29.

Rihova L., Hrabetova E. \& Tupy J. 1996. Optimization of Conditions for in vitro pollen germination and tube growth in potatoes. Int. J. Plant. Sci. 157(5): 561-566.

Robinson H. 1978. Studies in the Heliantheae (Astereceae). XII. Re-establishment of the genus Smallanthus. Phytologia 39 (1):47-53.

Roitman G. 1999. Pollination biology of Grindelia covasii (Asteraceae) a potencial crop for arid lanas. Journal of Arid environments. 43: 103-110.

Rozen S. and Skaletsky H. 2006. Primer3 Whitehead Institute for Biomedical Research, Cambridge, MD, USA. http://primer3.sourceforge.net/
Sabar M., Gagliardi D., Balk J. \& Leaver C., 2003. ORFB is a subunit of $F_{1} F_{0}$ - ATP synthase: insight into the basis of cytoplasmic male sterility in sunflower. EMBO Reports Vol. 4, No 4: 381 - 386.

Seminario J., Valderrama M. \& Manrique I. 2003. El yacón: fundamentos para el aprovechamiento de un recurso promisorio. Centro Internacional de la Papa (CIP), Universidad Nacional de Cajamarca, Agencia Suiza para el Desarrollo y la Cooperación (COSUDE), Lima, Perú, $60 \mathrm{p}$.

Soto A. 1997. Planta Llacón. Universidad Nacional de Cajamarca. Cajamarca, Perú.

Valla J. J. 1973. Morfología de las plantas superiores. Ed. Hemisferio Sur. Argentina.

Yu D., Kotilainen M., Pollanen E., Mehto M., Elomaa P., Healiutta Y., Albert V.A. \& Teeri T.H. 1999. Organ identity genes and modified patterns of flower development in Gerbera hybrida (Asteraceae). The Plant Journal 17(1), 51-62.

Trognitz B. 1991. Comparison of different pollen viability assays to evaluate pollen fertility of potato dihaploids. Euphytica 56: 143-148.

Vaknin Y., Mills D. \& Benzioni A. 2003. Pollen production and pollen viability in male jojoba plants. Industrial Crops and Products 18. P. $117-123$.

\footnotetext{
${ }^{1}$ Universidad Nacional Agraria La Molina, Dpto. de Biología. Lima Perú. rmansilla@lamolina.edu.pe

${ }^{2}$ Universidad Nacional Agraria La Molina, Dpto. de Biología. Lima Perú. cflb@lamolina.edu.pe

${ }^{3}$ Universidad Nacional Agraria La Molina, Dpto. de Biología. Lima Perú. mflores@lamolina.edu.pe

${ }^{4}$ Universidad Nacional Agraria La Molina, Dpto. de Biología. Lima Perú. respejo@lamolina.edu.pe
} 